\title{
Revolucionarios y bandidos: la trayectoria villista en la Revolución mexicana*
}

\author{
MARIA APARECIDA DE S. LOPES**
}

\begin{abstract}
Resumo: As últimas décadas do século XIX no México podem ser caracterizadas por três aspectos: estabilidade política, desenvolvimento econômico, e, conseqüentemente, de relativa tranqüilidade social. No contexto revolucionário, em contraste, se assiste ao rompimento desse status quo. Neste artigo, a partir dos relatos de alguns personagens comprometidos com o movimento armado, traçarei um panorama a respeito dos problemas da violência e da criminalidade, entre os anos 1910 e 1920, no norte do país.

Abstract: In the last decades of the $19^{\text {th }}$ century the Mexican society went through a period of political and economical stability, and relative social tranquility. On contrast, during the revolutionary context various armed movements promoted the disruption of this status quo. In this article, by the analysis of several testimonies, I intend to show some aspects regarding criminality and violence phenomena, during the 1910 and 1920 years on the Northern Mexico.
\end{abstract}

Palavras-chave: Revolução mexicana. Banditismo. Criminalidade.

Key words: Mexican Revolution. Banditry. Criminality.

\section{Introducción}

En otro trabajo he analizado el tema de la criminalidad en Chihuahua, México, a partir del fortalecimiento de los mecanismos de justicia durante el porfiriato (1876-1910). ${ }^{1}$ Un periodo que a grosso modo es calificado como de relativa estabilidad económica y social. Pero ¿cómo extender este análisis al contexto de la Revolu-

* Una versión preliminar de este artículo fue presentada en el VI Encontro da ANPHLAC (Associação Nacional de Pesquisadores de História Latino-Americana e Caribenha), realizado en la Universidade Estadual de Maringá, entre los días 20 y 23 de Julio, 2004.

* Professora de História da América na UNESP - Universidade Estadual Paulista, Franca, São Paulo. E.mail: souza@franca.unesp.br

1 LOPES, Maria Aparecida de S. Abigeos, bandidos sociales y "malhechores facciosos". Criminalidad y justicia en el estado de Chihuahua. 1876-1920. México: El Colegio de México, 1999 (tesis doctoral).

Estudos Ibero-Americanos. PUCRS, v. XXXI, n. 1, p. 79-100, junho 2005 
ción mexicana (1910-1920), cuando los "aparatos de justicia" así como las definiciones de "orden" y "legalidad" que el Estado imponía adquirieron significados bastante singulares? En este aspecto me topé con un serio problema metodológico. Si para el análisis del porfiriato pude contar con una amplia variedad de fuentes judiciales, el periodo posterior a 1910 - debido al paulatino resquebrajamiento del Estado y de sus medios coactivos - se caracterizó precisamente por la ausencia de esta documentación. Por otro lado, es igualmente difícil, a veces prácticamente imposible juzgar quién era considerado como un "fuera de la ley" durante la etapa armada de lo que posteriormente se conocería como la Revolución mexicana.

Los inconvenientes - de carácter teórico y metodológico - son tantos y tan complejos que por su sola naturaleza desalentarían la empresa que me propongo llevar a cabo. Sin embargo y quizá por lo mismo, se presenta como una oportunidad para hacer un ejercicio analítico, en el cual ciertas hipótesis no podrán ser probadas y que quizá concluya con más preguntas que respuestas. En todo caso, se podrá abrir una discusión sobre el controvertido tema para que estudios venideros, con base en nuevos enfoques y hallazgos documentales, vayan más allá de lo aquí propuesto. Me propongo a presentar algunos lineamientos generales acerca del problema de la criminalidad durante la Revolución de 1910 en Chihuahua. Dada la dificultad en recabar fuentes judiciales mi objetivo fue captar las opiniones de los distintos sectores sociales que estuvieron involucrados en el movimiento armado y trazar un mosaico de impresiones acerca de los problemas de la "violencia" y de la "criminalidad" durante el periodo comprendido entre 1910 y 1920 en el estado.

Durante las últimas décadas del siglo XIX en México, las alianzas entre diversos grupos de poder - elite, intelectuales, empresarios nacionales y extranjeros y clase política - permitieron dar cauce a un "proyecto de sociedad" que, entre otras cosas definía cuáles eran los intereses que el aparato judicial tendría que proteger y quiénes eran los considerados como "fueras de la ley". En el contexto revolucionario, en cambio, ocurrió el momento de resquebrajamiento de este consenso. En este periodo conceptos alrededor de los cuales la elite y los administradores del Estado habían entablado consenso, tales como "bandido" y "criminal", pierdieron sentido y adquierieron otros en función de la composición de fuerzas de las facciones revolucionarias en pugna; este artículo trata precisamente de esta transición y propone una vía de análisis para captar este proceso de cuestionamiento del orden jurídico porfiriano. 


\section{Bandidos y/o revolucionarios: los primordios de la revolución}

En esta sección se describirá el problema del bandolerismo entre 1910 y 1915 en Chihuahua, a partir de los testimonios de algunos contemporáneos del movimiento revolucionario en el estado. Como se verá, en la primera fase de este periodo o hasta 1915, la indecisión ante los acontecimientos revolucionarios determinó, en cierto sentido, el carácter moderado de estas declaraciones. Además, la inexistencia de un proyecto dominante, hizo con que cada facción armada buscara los medios para legitimar sus acciones - incluidas las expropiaciones - por un lado, con el apoyo de grupos de interés que pudiesen sostener económicamente al movimiento y por otro, descalificando en calidad de "bandidos" a sus oponentes.

El relato acerca de la Revolución de Baudilio Caraveo Estrada, ${ }^{2}$ en la región serrana al oeste de Chihuahua es una fuente esencial porque en ella se pueden captar la vivencia de un protagonista del movimiento armado en el estado - dudas personales, trato con los subordinados, formas de reclutamiento, préstamos forzosos, etc. - y además, una versión particular de los hechos nacionales que encauzaron la Revolución social durante sus primeros años. En su descripción se percibe una clara intención de legitimar el movimiento ante la sociedad, ello en sus palabras significaba inspirar confianza y dar garantías a la población local: vecinos, empresas y trabajadores "porque así [decía] nos colocábamos en el lado opuesto al bandolerismo". ${ }^{3}$ No obstante el cuidado del protagonista, el tachar de bandoleros a los miembros de los grupos armados en estos años en México fue una práctica tan generalizada, que de ello no escapó prácticamente ninguna facción alzada. En general, la definición dependió mucho más de los intereses y visión de los acontecimientos del observador y, en menor medida de la ideología o plan político que el grupo rebelde decía secundar. Así, bandidos fueron, según el grupo que adquiría preeminencia política, todos aquellos que continuaban luchando y desconocían al orden establecido, o que se buscaba consolidar, durante estos inestables años de luchas armadas en México.

2 Baudilio B. Caraveo Estrada fue representante antirreeleccionista de la municipalidad de Moris (distrito Rayón) en las elecciones presidenciales de 1910. Al inicio del movimiento armado se integró al contingente de Francisco I. Madero en Chihuahua, ocupando el rango de Mayor en el ejército revolucionario y enseguida participó como delegado villista en la Convención de Aguascalientes.

3 CARAVEO ESTRADA, Baudilio. Historias de mi odisea revolucionaria. La Revolución en la sierra de Chihuahua y la Convención de Aguascalientes. Chihuahua: Doble Hélice Ediciones, 1996, p. 135. 
Hacia principios de 1911 el jefe político del distrito de Bravos se refería a los maderistas del siguiente modo: "[...] los bandidos [...] tienen ya estos elementos y no se duermen, sino por el contrario con una actividad increíble día a día se buscan mayor número de adeptos [...]". ${ }^{4}$ Una vez en el poder a los maderistas les tocaría calificar de bandoleros y gavilleros a sus contrincantes. 5 Tres años después, intentando neutralizar su creciente oposición, los huertistas clamaban a la población a "reunirse al lado de una bandera honrada y que lucha por salvar a la patria de las chusmas de bandoleros...". 6 El grado de subjetividad en la utilización del término fue tan grande y variado en la época que, como lo ha notado Alan Knight, "no resulta adecuado para una explicación histórica".7

Después de 1910 grupos de vecinos armados surgieron en distintas partes de la república. Unos para defender sus negocios, como algunos representantes de minerales en Lluvia de Oro en el distrito Andrés del Río, al oeste de Chihuahua. ${ }^{8}$ Otros con objetivos políticos limitados y poca organización militar. ¿Serían "grupos de malhechores que, a la sombra de los grupos sediciosos, buscan tan sólo su medio individual, dedicándose al robo, al plagio, y a la comisión de toda clase de crímenes en contra de las personas y propiedades", como lo afirmó Alberto Terrazas?9 Sin duda este reclamo del gobernador, formulado en enero de 1911, así como la mayoría de las declaraciones de sus contemporáneos, contienen una carga ideológica que nos obliga a tomarlas con ojo crítico, sopesando el contexto y las intenciones del narrador.

La diferenciación que se puede establecer entre el "soldado" y el "bandido" en momentos de resquebrajamiento del orden es extremadamente tenue. 10 En este sentido existen reiteradas descripcio-

4 Colección Porfirio Díaz - Universidad Iberoamericana (en adelante CPD), 27/enero/1911, legajo XXXVI, doctos. 003037-003040, carta del jefe político del distrito de Bravos a Porfirio Díaz. Subrayado mío.

5 Archivo General de la Nación, Ciudad de México (en adelante AGN), Fondo Gobernación, 23/mayo/1911, 1a. sección, caja 16, exp. 2, telegrama de Jorge Vera Estañol a Francisco I. Madero.

6 Archivo Histórico de la Secretaría de la Defensa Nacional, Ciudad de México (en adelante AHSDN), Fondo Revolución, 03/marzo/1914, caja 28, exp. XI/481.5/70, t. I, carta de José Justiniani y otros. Subrayado mío.

7 KNIGHT, Alan. La Revolución mexicana. Del porfiriato al nuevo régimen constitucional. México: Grijalbo, 1996, p. 394, 2 v, v. 1.

8 Caraveo Estrada, op. cit., 1996, p. 89.

9 Periódico Oficial del Estado de Chihuahua, Chihuahua (en adelante POECH), 01/enero/1911.

10 VANDERWOOD, Paul J. Desorden y progreso. Bandidos, policías y desarrollo mexicano. México: Siglo Veintiuno, 1986, p. 53; TAYLOR, William B. Bandolerismo e insurrección: agitación rural en el centro de Jalisco, 1790-1816. In: Katz, Friedrich (comp.). Revuelta, rebelión y Revolución. La lucha rural en México del siglo XVI al siglo XX. México: Ediciones Era, 2 tomos, 1990, p. 188, t. 1. 
nes acerca de las dificultades que los altos mandos maderistas enfrentaron durante el periodo de armisticio en Chihuahua. No hay duda de que en este contexto, muchos de estos hombres insatisfechos con su "nueva" situación volvían a la vida pública - como miembros de pequeñas gavillas sin ambiciones políticas o facciones ideológicas rivales - con fuerza suficiente para erosionar la frágil legitimidad de un gobierno que recién se estaba formando.11 Este caso entre las filas maderistas fue común. De acuerdo con el general Fernando Trucy Aubert muchos soldados "no han quedado conformes con su liquidación creyendo sacar mejor partido de la revolución, la mayor parte de los licenciados no quisieron vender sus armas llevándoselas consigo...". ${ }^{12}$

Durante los primeros años de la Revolución las acciones deliberadas en contra de la propiedad y las personas no fueron actos generalizados. Pese a las advertencias de la administración regional, el claro descontento entre algunos grupos y la dispersión de algunas bandas armadas - aparentemente sin objetivos definidos - los ataques a la propiedad parecen no haber sido desmedidos. ${ }^{13}$ La información de las empresas intervenidas, así como los reportes de la secretaría de Guerra indican que todavía en este periodo los gavilleros, interesados única y exclusivamente en el pillaje constituían más bien casos aislados. 14

Desde el otoño de 1910 hubo algunos blancos preferidos por los grupos rebeldes - ferrocarriles, grandes propiedades, empresas extranjeras - quienes a juzgar por la información oficial tenían el respaldo de la población. En diversas ocasiones las autoridades militares porfiristas se refirieron al limitado aprecio que los vecinos mostraban por sus tropas y a la imposibilidad de reclutar efectos y hombres entre éstos, debido al apoyo que ofrecían a las filas rebeldes. ${ }^{15}$ De ello da cuenta esta autoridad militar porfirista:

11 VANDERWOOD, Paul J. Los bandidos de Manuel Payno. In: Historia Mexicana, vol. 44, no. 1, 1994, p. 130-131.

12 AHSDN, Fondo Revolución, sin fecha, caja 25, exp. XI/481.5/67, t. I.

13 El Correo de Chihuahua, 21/octubre/1911; BEEZLEY, William H. Insurgent Governor. Abraham González and the Mexican Revolution in Chihuahua. Lincoln: University of Nebraska Press, 1973, p. 61; HART, John M. The Revolutionary Mexico. The Coming and Process of the Mexican Revolution. Berkeley: University of California Press, 1987, p. 259.

14 Ello desde luego no supone la "inexistencia" de este tipo de grupos a fines de 1911. En este periodo se tiene noticias de partidas que operaban sobre todo en la zona oeste del estado, sacrificando reses sólo para utilizar el cuero o consumir un pedazo de carne y cometiendo plagios. Según se relataba "vivían en las haciendas y ranchos cercanos y eran bien conocidos", In: El Correo de Chihuahua, 21/octubre/1911.

15 AHSDN, Fondo Revolución, 19/marzo/1911, caja 19, exp. XI/481.5/63, t. III, carta del coronel Agustín Valedes; 21/marzo/1911, caja 21, exp. XI/481.5/63, t. V, carta de Juan Hernández a la secretaría de Guerra. 
ahora los revoltosos han acabado con las pasturas de los ranchos y Haciendas. El agua también es escasa, y si a todo esto se agrega la falta de voluntad que está demostrando para nuestras tropas, la mayor parte de los habitantes, encontrará usted explicarlo, porque algunas veces han pasado hasta treinta horas, sin que una fuerza de caballería encuentre pasturas. ${ }^{16}$

Distintas fuentes confirman el rechazo de población chihuahuense a las tropas federales y la simpatía y contribución en favor de las fuerzas rebeldes. ${ }^{17}$ Sin embargo, a partir del momento en que Francisco Madero empezó a asumir sus funciones como gobernante estas alianzas y en cierto sentido "el consenso" que se había gestado alrededor de su programa se fueron debilitando. Los sectores que se oponían al programa maderista se dispersaban entre grupos afiliados al Partido Liberal Mexicano (PLM) - algunos de los cuales apoyaron al orozquismo - sectores más populares de indefinida filiación ideológica, liberales e incluso colaboradores de los Terrazas, que vieron en la figura de Pascual Orozco ${ }^{18}$ una posibilidad de frenar los avances reformistas de Abraham González. ${ }^{19}$

Pese a que se puede verificar un aumento de la violencia, sobre todo a partir de 1912, en Chihuahua no parece haber habido un bandidaje generalizado o "profesional" en este periodo. Uno u otro bando que se alzaba - aunque de origen "dudoso" - solía afiliarse a un líder político lo que permite considerarlo más bien como fuerza rebelde. En este caso cuando la documentación oficial los tacha de bandidos, ello se debió más a la oposición que de facto estos grupos estaban ejerciendo, que a los ataques a la propiedad y a las personas a ellos atribuidos. ${ }^{20}$

16 AHSDN, Fondo Revolución, sin fecha, caja 18, exp. XI/481.5/62, t. III, carta de Juan Hernández a Porfirio Díaz. En otra carta se afirma que el ejército no contaba ni siquiera con el apoyo de los elementos de la guardia nacional, ya que se les consideraba en su mayoría maderistas "y no se les tiene entera confianza". In: AHSDN, Fondo Revolución, 08/enero/1911, caja 14, exp. XI/481.5/61, t. II, carta del teniente coronel Manuel Reyes.

17 Despatches from United States Consuls in Chihuahua, (en adelante USA consuls), 06/marzo/1911, carta del vicecónsul C. M. Leonard a la secretaria de estado, Washington; AGN, Fondo Gobernación, 25/febrero/1911, sin sección, caja 11, exp. sin número carta de Enrique Creel al secretario de Gobernación; El Correo de Chihuahua, 31/marzo/1911.

18 Pascual Orozco fue, uno entre otros líderes exmaderistas, que continuaron en pie de lucha después de 1911.

19 Knight, op. cit., 1996, p. 345-347, vol. 1; KATZ, Friedrich. The Life and Times of Pancho Villa. Stanford: Stanford University Press, 1998, p. 131-134; CARAVEO, Marcelo. Memorias del general don Marcelo Caraveo. s/e, s/f, p. 65-71.

20 Records of the Ferrocarril Noroeste de México 1910-1919, Benson Latin American Collection, General Libraries, University of Texas at Austin, (en adelante RFNM), 29/enero/1914, caja 4, fólder 12, carta sin remitente. 
No hay demasiados indicios de una irrupción masiva de facciones armadas, sin pretensiones sociales, por lo menos durante los primeros años del movimiento armado en Chihuahua. Otro elemento que confirma esta información se refiere a los blancos preferidos de los alzados: parque, caballos, armas y provisiones eran robados en las haciendas y ranchos; por otra parte, en las compañías mineras el administrador y la tienda de raya raramente pasaban inadvertidos. ${ }^{21}$ Asimismo, el constante ataque a las posesiones de Luis Terrazas echa por tierra la supuesta "irracionalidad" generalmente imputada a algunos grupos rebeldes y hacen considerar cierta intencionalidad en sus amenazas y ataques a la propiedad privada. En Galeana, las propiedades de Luis Terrazas y de Enrique Müller fueron ocupadas por los villistas durante el periodo en que la División del Norte controló Chihuahua. ${ }^{22}$

Vale recordar que desde los inicios del movimiento, Luis Terrazas sufrió el rechazo de sus trabajadores para defender su propiedad. El general se quejaba que sus "peones" no le habían sido leales "desde el principio de la situación estoy haciendo esfuerzos por armar gente de mis haciendas; pero con franqueza vuelvo a manifestar a usted que los mismos sirvientes están muy contaminados, y solamente se cuenta con un reducidísimo número que son leales...". ${ }^{23}$ Según uno de los administradores de la Compañía Corralitos a principios de 1911, "los insurrectos ha[bían] depredado prácticamente todos los ranchos de caballos de los Terrazas y de los demás propietarios mexicanos...". ${ }^{24}$ En una carta dirigida al secretario de Gobernación, el exgobernador relató que las haciendas El Torreón, San Lorenzo, Encinillas, San Luis y el Rancho de Avalos, habían sido sistemáticamente saqueadas, afirmando que

21 El Correo de Chihuahua, 27/marzo/1911; 13/abril/1911; 08/junio/1911.

22 NUGENT, Daniel. Spent Cartridges of Revolution. An Anthropological History of Namiquipa, Chihuahua. Chicago and London: The University of Chicago Press, 1993, p. 78.

23 Citado en FUENTES MARES, José. Y México se refugió en el desierto. Luis Terrazas: Historia y destino. México: Editorial Jus, 1954, p. 244, 20/enero/1911, carta de Luis Terrazas a Enrique Creel.

24 Thomas Wentworth Peirce, Jr. Papers, 1900-1923, Benson Latin American Collection, General Libraries, University of Texas at Austin (en adelante TWP), 22/febrero/1911, caja 1, fólder 10, carta de E. C. Houghton. Traducción libre.

Haciendo alusión a los ataques a las propiedades de Luis Terrazas, las autoridades españolas prácticamente justificaban a los rebeldes "Chihuahua que gradualmente surge a la vida, minería, agricultura, ferrocarriles, ha venido siendo un feudo del General Terrazas, anciano, fuerte y recio todavía, y de sus numerosos deudos, acaparadores y propietarios de inmensos terrenos (...) y desde luego el éxodo del General Terrazas y los suyos ha sido total, sirviendo sus haciendas al sostén de los alzados". En Archivo Histórico de la Embajada de España en México (en adelante AHEEM), 12/febrero/1911, legajo 1, n. 07, carta al ministro de estado español. 
es público y notorio que yo he sido uno de los propietarios que más ha sufrido en el Estado de Chihuahua, desde que se inició la revolución (...). Es del dominio público que durante la revolución más de tres mil insurrectos vivieron en algunas de mis haciendas, por varios meses, estableciendo en ellas su cuartel general, disponiendo de todo lo que en ellas se encontraba, sacrificando un sinnúmero de reses, agotando las semillas que allí se almacenaban y apoderándose de más de tres mil caballos, y una cantidad de mulas, guarneces, (sic) sillas y de cuanto tenían antojo o necesidad. ${ }^{25}$

Al lado de Luis Terrazas, otros nacionales tales como los $\mathrm{Zu}$ loaga, ${ }^{26}$ y los negocios de los estadounidenses - que incluso pudieron contar con la protección del gobierno y autoridades locales hasta mediados de 1911, cuando todavía se reportaron la persecución y aprehensión de asaltantes en el distrito de Jiménez ${ }^{27}$ - fueron otros blancos de los alzados. Sin embargo, a principios de la rebelión maderista, los reportes de algunas empresas y los informes consulares hablan de una total tranquilidad en determinadas regiones de Chihuahua y que incluso ciertos negocios pudieron continuar operando sin mayores dificultades: "México se encuentra completamente restablecido [afirmaba un funcionario del Ferrocarril del Noroeste de México] no se constatan daños a nuestra propiedad o interferencia a sus operaciones; los reportes acerca de los disturbios, los cuales sin sentido condenan la revolución, han sido grandemente exagerados". ${ }^{28}$ En efecto, en estas primeras expropiaciones la mayoría de los grupos tenía el cuidado de expedir vales justificando de esta manera la intervención, tal como lo relata este observador "pese a que ellos [los rebeldes] se apropiaron de alguna munición de las tiendas, ofreciendo unos recibos en cambio; [...] estos recibos tendrán validez en caso de que un nuevo gobierno sea establecido". ${ }^{29}$

25 AGN, Fondo Gobernación, 28/julio/1911, sin clasificar, caja 1, exp. 1, carta de Luis Terrazas al secretario de Gobernación.

26 El Correo de Chihuahua, 16/julio/1912.

27 AGN, Fondo Gobernación, 26/abril/1911; 08/mayo/1911, 1a. sección, caja 15, exp. 2, carta de Miguel Ahumada al secretario de Gobernación; carta al secretario de Guerra y Relaciones Exteriores.

28 RFNM, 24/noviembre/1910, caja 1, fólder 2, telegrama de F. S. Pearson, traducción libre; 26/noviembre/1910, carta sin remitente; 15/diciembre/1910, carta a H. C. Ferris; TWP, 20/enero/1911, caja 1, fólder 9, carta de E. C. Houghton. La apreciación del ministro plenipotenciario de España en México era similar. In: AHEEM, 01/enero/1911, legajo 1, no. 1, carta de Bernardo Jacinto de Cólogan y Cólogan.

29 TWP, 04/enero/1911, caja 1, fólder, 9, carta de W. G. Laird a C. I. Reeves. Traducción libre. Un ranchero estadounidense residente en Chihuahua afirmó que "durante la revolución maderista su propiedad había sido visitada frecuentemente por los rebeldes, quienes le forzaron a 'contribuir' desprendidamente con la rebelión. En estos 
A partir de 1911 estas bandas rebeldes adoptaron un comportamiento típico de la mayoría de los alzados que tomaban una plaza: atacaban a las propiedades privadas, liberaban a los presos de las cárceles, destruían los documentos judiciales y saqueaban las tiendas locales. ${ }^{30}$ Pese a la propaganda de El Correo de Chihuahua en contra de las campañas orozquistas, quienes invariablemente eran denominados "gavilleros" y "ladrones", 31 su modus operandi se asemejaba en muchos aspectos al de los villistas. La observación de uno de los miembros de la Compañía Corralitos deja bastante clara la incertidumbre que compartían muchos de los espectadores ante las vicisitudes del movimiento armado: "Cuando nosotros nos damos cuenta de que Villa, quien representa el Gobierno Federal, está robando a los rancheros, mientras que por otro lado, Rojas, representando a los Revolucionarios, hace lo mismo, el panorama se ve bastante confuso". 32 Para otros contemporáneos la situación no era tan mala. De acuerdo con un reporte preparado por el senador estadounidense Albert Fall, los periódicos exageraban en cuanto a la intensidad de los robos, pese a que algunos caballos y otros enseres habían sido expropiados, "muchas de las propiedades han sido devueltas más tarde o pagadas. Los revolucionarios en la mayoría de los casos entregan recibos o prometen pagar lo que se llevan".33

El colapso del maderismo vino acompañado de un aumento de la violencia, fundamentalmente debido a la quiebra de la "unidad" entre los propios grupos o mini-grupos revolucionarios, quienes reclamaban para sí la legitimidad de la Revolución. ${ }^{34}$ No obstante, hacia mediados de 1912, aunque los ataques a la propiedad se incrementaron, todavía se encuentran reportes como el que reproducimos en seguida, en el que se relata la situación en ciudad Madera:

meses, caballos, provisiones entre otras cosas habían sido cedidas de manera 'provisional' [a los rebeldes, quienes] le dieron a cambio un recibo como promesa de que él será reembolsado, cuando la revolución triunfe". In: El Paso Herald, 24/diciembre/1912, traducción libre; El Correo de Chihuahua, 07/agosto/1912.

30 RFNM, 01/febrero/1911, caja 1, fólder 12, carta de D. F. Bucher a H. C. Ferris; USA consuls, 21/octubre/1912, carta de Marion Letcher al secretario de Estado, Washington; El Correo de Chihuahua, 07/febrero/1912; 08/febrero/1912; 23/febrero/ 1912.

31 El Correo de Chihuahua, 16/julio/1912.

32 RFNM, 22/febrero/1911, caja 1, fólder 14, carta de H. C. Ferris a H. I. Miller. Traducción libre.

33 Citado In: MEYER, Michael. El rebelde del norte. Pascual Orozco y la Revolución. México: Universidad Nacional Autónoma de México, 1984, p. 107.

34 TUTINO, John. Revolutionary Confrontation, 1913-1917. Regional Factions, Class Conflicts, and the New National State. In: Thomas Benjamin \& Mark Wasserman (coords.). Provinces of the Revolution. Essays on Regional Mexican History. 1910-1920. Albuquerque: University of New Mexico Press, 1990, p. 43. 
Esta mañana todo está perfectamente calmado, aunque hay aproximadamente 400 hombres de la caballería en la ciudad. Nada sucedió la noche anterior. Hubo una o dos peleas callejeras, pero en lo demás todo estuvo extremadamente ordenado. La Oficina de Telégrafos está todavía abierta, la Oficina de Correo y los edificios Federales están cerrados y sus empleados han abandonado la ciudad. Todos los empleados de los ferrocarriles han huido, llevando consigo sus familias. Aunque los Rebeldes hayan cometido faltas, debemos darles crédito por no haber saqueado la ciudad y por la manera caballerosa en que trataron esta ciudad. ${ }^{35}$

En algunos relatos ciertos revolucionarios son descritos con cierta "simpatía". En una ocasión un coronel fue definido como un "hombre muy amable" debido a la devolución de unos caballos que habían sido confiscados a la compañía del Ferrocarril del Noroeste de México en Madera. José Inés Salazar - en este momento secundando al orozquismo - también ordenó la devolución de bienes a los agricultores mormones en Casas Grandes. ${ }^{36}$ Pese al recrudecimiento del sentimiento anti-extranjero - lo que se observa ante los asaltos a las colonias de los mormones, en los cuales se confiscaban armas, municiones, dinero y caballos diversos grupos todavía ofrecían protección a sus vidas e intereses. En otros casos queda claro que el motivo de los ataques a la propiedad era el hambre. ${ }^{37}$ Tampoco abunda la información sobre atentados en contra de las personas, en diversas ocasiones se reportaron asaltos en los que las vidas de los extranjeros fueron respetadas y en otros incluso se devolvió el botín. ${ }^{38}$

35 RFNM, 05/julio/1912, caja 1, fólder 19, carta de D. B. Gillis. Traducción libre.

36 RFNM, 13/julio/1912, caja 1, fólder 21, carta a J. O. Crockett; TWP, 25/febrero/1911, caja 1, fólder 10, carta de E. C. Houghton; El Correo de Chihuahua, 18/julio/1912.

37 RFNM, 27/julio/1912, caja 2, fólder 5, carta de H. I. Miller a F. S. Pearson; 28/julio/1912, caja 2, fólder 6, carta de J. O. Crockett a E. H. Clark; 01/febrero/1913, caja 2, fólder 17, carta de A. H. Duderstadt a J. J. Pruett; TWP, 13/julio/1912, caja 1, fólder 10, carta de E. C. Houghton; El Paso Herald, 12/agosto/1912, en este artículo se describe la situación en que se encontraba el grupo que asaltó a la colonia Dublán: "La primera comida ha sido terrible. La gente estaba hambrienta y no había nada en el campo excepto un poco de harina y tocino, no había sal o pimienta [...]. Los sacos de harina fueron abiertos, y cada hombre tomó un poco de agua, mezcló con un poco de harina [...] que fue cocida en las cenizas....". Traducción libre.

38 USA consuls, 05/diciembre/1912, carta del cónsul T. D. Edwards al secretario de estado, Washington; TWP, 20/julio/1912, caja 1, fólder 10, carta de E. C. Houghton; 31/julio/1912, caja 1, fólder 10, carta sin remitente; AHEEM, 23/febrero/1912, legajo 6, no. 5, carta de Manuel Walls y Merino; El Correo de Chihuahua, 27/dicembre/1912. 
Sin embargo, la guerra civil desencadenada durante el régimen huertista y la decadencia de la situación económica en Chihuahua desestabilizaron aun más el panorama social en el estado. A partir de febrero de 1913 cuando las fuerzas huertistas derrocaron a Madero, se hicieron más constantes las denuncias de "numerosas cantidades de pequeñas bandas" operando - quizá de manera independiente - sobre todo en la región noroeste del estado. ${ }^{39}$ Los asaltos a las personas parecían haberse tornado más audaces ${ }^{40}$, tal como lo relata un funcionario del Ferrocarril del Noroeste de México:

La planta de fundición de Chihuahua está cerrada, y ha permanecido así por algún tiempo. Los comestibles en Chihuahua están limitados, y es imposible conseguir vegetales, mantequilla, huevos, carne fresca y otros productos. Los fósforos son vendidos a 50 centavos la caja. El azúcar se vende a $\$ 1.50$ el kilo y el café a \$2.00 el kilo. [...].

Stevenson está bien informado acerca de las condiciones en el estado de Chihuahua en general, ha estado hablando con muchos americanos que tienen intereses en el estado, y todos expresan la opinión de que las condiciones ahora están mucho peores de lo que habían estado en otros momentos de la revolución, y que no hay absolutamente ninguna solución a la vista; de hecho, ellos están esperando que las condiciones empeoren [...], pues el estado de Chihuahua es sin duda un lugar peligroso para cualquier extranjero. ${ }^{41}$

Fue también en este momento cuando los estadounidenses empezaron a solicitar, de manera más insistente, la intervención de su gobierno en el rumbo de los acontecimientos en México. Se incrementaron los asaltos en contra de los empleados organizados en guardias para la defensa de sus empresas, tal como se reportó en numerosas ocasiones en Madera. ${ }^{42}$

No obstante, el rumbo de los acontecimientos fue alterado a partir del momento en que la División del Norte empezó a adueñarse de la situación político-militar en Chihuahua. En los reportes

39 RFNM, 04/febrero/1913, caja 2, fólder 18, carta a T. G. Hay; 21/julio/1913, caja 4, fólder 4, carta sin remitente.

40 El Paso Herald, 27/agosto/1913; RFNM, 29/enero/1914, caja 4, fólder 12, carta de J. O. Crockett; 07/febrero/1914, caja 4, fólder 13, telegrama de H. I. Miller; AHEEM, 22/abril/1913, legajo 4, no. 1, carta de Francisco C. de la Barra.

41 RFNM, 17/julio/1913, caja 4, fólder 4, carta de J. O. Crockett a H. I. Miller, traducción libre; AHEEM, 28/abril/1913, legajo 4, no. 14, carta sin remitente. Esta impresión es confirmada por Marcelo Caraveo, quien se refiere constantemente a la escasez de géneros y a la carestía en Chihuahua, en Caraveo, s/f, p. 76-91.

42 RFNM, 19/julio/1913, caja 4, fólder 4, telegrama de L. C. Griscon al secretario de estado, Washington; 21/julio/1913; caja 4, fólder 4, sin remitente; 22/julio/1913, caja 4, fólder 5, telegrama de H. I. Miller a Luis Riba. 
de los funcionarios del Ferrocarril del Noroeste de México se nota un poco más de confianza, entre otros motivos porque el propio Villa les había prometido protección militar. En efecto, a principios de 1914 ya se había logrado la reanudación de la actividad de los trenes principalmente en la región norte de país, en los estados de Chihuahua, Coahuila, Tamaulipas, Nuevo León y Zacatecas, así como el tráfico más fluido de ganado, metales y mercancías en general. ${ }^{43}$ Durante este periodo se gozó en Chihuahua de relativa seguridad y a la vez se manifestó una ligera mejora en la situación económica local, "...no hay hambruna en Chihuahua [relata un periódico fronterizo], de acuerdo con los comerciantes americanos de la ciudad, [quienes] han abierto sus tiendas y llevado hacia adelante sus negocios". ${ }^{44}$ Aunque esta última impresión no fuera del todo imparcial, es una pequeña señal de confianza de parte del grupo de inversionistas extranjeros más importante en el estado, los estadounidenses.

Y ello abrió un capítulo particular en la historia de la Revolución en Chihuahua, la relativa tranquilidad relatada en algunos informes consulares y en los reportes de las empresas estadounidenses en el estado se debía en gran medida a las garantías que los villistas habían ofrecido a los intereses norteamericanos, ya que éstos controlaban los principales negocios que permitirían sostener no sólo la estructura económica regional sino también financiar las campañas militares de la División del Norte. Las buenas relaciones entre villistas y estadounidenses permitieron incluso que algunos ciudadanos que habían huido a Estados Unidos regresen a Chihuahua a principios de 1914.45 Según Friedrich Katz, la instauración del gobierno militar villista en el estado logró dar cierto sentido de cohesión social y ello posibilitó que las consecuencias de la guerra fueran menos dramáticas entre la población chihuahuense. Incluso en Ojinaga, uno de los únicos bastiones orozquistas en la época, los rancheros armaban a sus peones secundando a Pancho Villa. ${ }^{46}$ Las reformas impuestas por la administración villista, tales como la restauración de la autonomía municipal, reducción de

43 RFNM, 15/noviembre/1913, caja 4, fólder 7, carta de A. L. Lathorp a H. I. Miller; 02/diciembre/1913, caja 4, fólder 8, carta de Francisco Villa; 31/diciembre/1913, caja 4, fólder 9, telegrama de H. I. Miller; 02/enero/1914, caja 4, fólder 10, telegrama de H. I. Miller.

44 El Paso Herald, 11/diciembre/1913. Traducción libre.

45 RFNM, 13/enero/1914, caja 4, fólder 10, carta de H. I. Miller; 23/enero/1914, caja 4, fólder 11, telegrama sin remitente.

46 AHSDN, Fondo Revolución, 28/mayo/1913, caja 27, exp. XI/481.5/69, t. II, carta sin remitente; Meyer, op. cit., 1984, p. 133-135. 
impuestos y la intervención de las propiedades de la oligarquía local recogían de cierta forma, parte de las demandas de muchos revolucionarios chihuahuenses, quienes retornaban a sus pueblos y ciudades con garantía de pensiones y provisiones a bajos costos. 47

A fines de 1913 un periódico de El Paso informó que "los ciudadanos de Chihuahua recibieron a los rebeldes con los brazos abiertos". ${ }^{48}$ La prensa fronteriza, tan interesada en el rumbo de los acontecimientos al sur del río Bravo, mostraba aires de optimismo y ello se debía además a la propaganda villista en materia de seguridad. ${ }^{49}$ La administración villista se encargó de eliminar las bandas armadas - quizá algunos de ellos orozquistas - que merodeaban sobre todo en la región noroeste del estado. Villa fue tenaz y persiguió como "bandoleros" a figuras que podían desestabilizar al régimen, ello porque los ataques a la propiedad no desaparecieron del todo. 50

Al lado de los desajustes institucionales provocados por la irrupción del movimiento armado continuó existiendo un nivel de conflicto que podríamos denominar "cotidiano". Todavía hasta 1915 encontramos un número significativo de procesos por robo de ganado. ${ }^{51}$ En un caso llevado a cabo en la ciudad de Chihuahua un ranchero, dueño de cuatro propiedades, afirmaba que "le han robado desde que empezó la revolución como dos mil reses en distintas épocas, semovientes que pastaban en campo abierto, sin que tenga sospecha de qué personas sean los autores". 52 De la misma forma también se llevaron a término causas por los delitos de homicidio y robo. En este aspecto se puede considerar que la administración de la "justicia", a pesar de los contratiempos, no se vio totalmente inte-

47 Katz, op. cit., 1998, p. 398 y ss; 1990.

48 El Paso Herald, 10/diciembre/1913. Traducción libre. A principios de ese año este periódico informaba: "Una muchedumbre se dirigió hacia Columbus, Nuevo México, [...]. Varios hombres bien vestidos estaban acompañados de un gran número de peones. Los mexicanos dijeron a los empleados del ferrocarril que iban a afiliarse al ejército de Pancho Villa, [...] para demostrar su oposición a Huerta...”. In: El Paso Herald, 02/marzo/1913. Traducción libre.

49 El Paso Herald, 20/diciembre/1913; 05/marzo/1914.

50 Ciudadanos estadounidenses de la línea fronteriza reclamaban constantemente depredaciones y ataques a la propiedad de parte de grupos armados de mexicanos, por ello solicitaban la intervención de cuerpos policiacos en la zona, In: El Paso Herald, 10/abril/1914; 14/abril/1914.

51 Archivo del Supremo Tribunal de Justicia del Estado de Chihuahua (en adelante ASTJECH), 01/febrero/1913, "Toca el proceso instruido contra Prisciliano Fierro por haber sacrificado clandestinamente dos cerdos", sin clasificación.

52 ASTJECH, 21/agosto/1913, "Causa criminal instruida contra Luis Alcalde por el delito de abigeato", sin clasificación. 
rrumpida durante los primeros años de la Revolución en Chihuahua y que además su "funcionamiento" se hacía con base en un conjunto legislativo que sostuvo en el poder al grupo que dichos revolucionarios estaban intentando derrocar: la constitución de 1857 y el código penal promulgado durante la década de 1880.53

La continuidad de la administración de la justicia es una muestra de que los individuos todavía podían acudir a esta instancia para dirimir conflictos relativos por ejemplo, a la propiedad ganadera, siempre y cuando no se tratase de querellas relativas a las expropiaciones de los grupos revolucionarios, ya que éstas se llevaban a cabo y se justificaban en un marco distinto al que se aplicaba para juzgar a los criminales "comunes". Después de 1915, sin embargo el número de expedientes judiciales disminuye considerablemente. Pese a que este dato no puede ser tomado como conclusivo, debido a que los archivos judiciales eran blancos de los grupos armados cuando tomaban una plaza, ello puede indicar que la administración de la justicia empezaba a enfrentar dificultades a partir de esta fecha.

\section{Bandidos versus revolucionarios: el triunfo Constitucionalista}

A partir de 1915 el panorama en Chihuahua estuvo marcado por dos eventos que pueden ayudar a explicar el cambio de actitud de los observadores hacía la Revolución en sí y hacia el villismo en particular: el rompimiento definitivo de la "unidad" revolucionaria y el paulatino fortalecimiento del grupo carrancista. A partir de este periodo Venustiano Carranza y adeptos parecían acercarse más a los observadores internacionales en el sentido de plantearse como la única alternativa para estabilizar al país. En efecto mucho, del bandidaje a que se hace alarde en este periodo se confunde con exrevolucionarios que continuaron en pie de lucha y que no aceptaron los términos de la legalidad que Carranza y aliados intentaban implementar.

53 ASTJECH, 23/marzo/1911, "Toca al proceso instruido por robo en contra de Francisco Nevarez", sin clasificación; 26/junio/1913, "Causa instruida contra Jesús José Carrillo por el delito de abigeato", sin clasificación; 02/agosto/1915, "Incidente de libertad bajo fianza promovido por el defensor de Juan Herrera, presunto responsable por el delito de robo", sin clasificación.

En el ámbito nacional la amplia legislación expedida durante los años revolucionarios se circunscribía básicamente al ámbito agrario y laboral y casi no tocó el aspecto judicial, en efecto el código penal posrevolucionario fue promulgado solamente en 1929. In: MARGADANT S. Guillermo F. Introducción a la historia del derecho mexicano. Neucalpan, Estado de México: Editorial Esfinge, 1994, p. 203-206, 244. 
Al lado de estos factores, la decadencia económica que se vivió en Chihuahua a fines de 1914 contribuyó al debilitamiento de la situación social en el estado. Desde principios de 1915 el papel moneda villista sufrió depreciaciones constantes. En mayo alcanzó su punto más bajo desde que se habían iniciado los combates armados: 4.5 centavos de dólar; dos meses después oscilaba entre 1.5 a 2.0 centavos. ${ }^{54}$ La relativa mejoría en las condiciones sociales que la administración villista había logrado a fines de 1913 y durante 1914 - por medio de la redistribución de alimentos y el control de los precios de los artículos de primera necesidad - si bien alivianó las penurias de parte de la población chihuahuense, en poco tiempo se mostró ineficaz ante el decaimiento militar de la División del Norte en el Bajío. En la medida en que se prolongaba el movimiento armado aumentaban las privaciones de los residentes. "Los precios de los alimentos están fuera de control. Es un misterio cómo pueden vivir los mexicanos...", decía un viajero estadounidense que visitó Chihuahua a mediados de 1915.55 Además de la escasez de productos como maíz, frijol, leche, carne y pan, los chihuahuenses se enfrentaban a una carestía incontrolable. .56

En la medida en que estos fenómenos se combinaban - sin dejar de lado la dispersión del ejército villista y la consecuente disgregación de partidas armadas que empezaron a actuar, quizá de manera independiente ${ }^{57}$ - se percibe el desmoronamiento de la legitimidad en torno al villismo. Ello es absolutamente claro en los informes consulares a partir de 1916, en los cuales ya se empezaban a hacer referencias constantes acerca de la existencia grupos dispersos en la región norte del país, sin explicar exactamente a qué facción pertenecían: en algunos casos se les define como exvillistas, en otros como excarrancistas, no quedando clara su afiliación a algún partido revolucionario. 58

54 El Paso Herald, 30/marzo/1915; 01/abril/1915; 15/mayo/1915; USA consuls, 31/julio/1915, carta de E. H. Booth y otros al cónsul Marion Letcher.

55 RFNM, 26/julio/1915, caja 5, fólder 3, carta a H. I Miller. Traducción libre.

56 ALMADA, Francisco. La revolución en el estado de Chihuahua. México: INEHRM, 2 tomos, 1964 , p. 235-236, t. 2.

57 USA consuls, 14/enero/1916, carta del cónsul T. D. Edwards al secretario de Estado, Washington; Archivo Lázaro de la Garza (en adelante ALG), 16/enero/1916, caja VI, fólder H, docto. 3, carta de R. E. Navarro.

58 Es evidente que la percepción de los estadounidenses acerca de Villa y su grupo estuvo condicionada por una serie de incidentes que comprometieron a los villistas en este periodo. Las sucesivas derrotas de la División del Norte en el Bajío y el apoyo estadounidense a Carranza - cuando había una posibilidad real de que reconociera al gobierno de la convención - fueron factores cruciales en el nuevo giro del villismo. Parte de esta frustración se ve plasmada en diversas acciones de los grupos guerrilleros en contra de las posesiones estadounidenses y quizá en el controvertido ataque 
De acuerdo con estos informes, estos "bandoleros" merodeaban el estado en bandas armadas cuya composición oscilaba entre 20 y 200 hombres. La mayoría actuaba en la región noroeste de Chihuahua, cometiendo asaltos de mediana magnitud: saqueos a tiendas y oficinas públicas, robos a haciendas y ranchos, y según decían los observadores, prevalecía un sentimiento antiextranjero. ${ }^{59}$ De acuerdo con el representante de la legación española en México, "lo único verdaderamente exacto es que en todo el país está el bandolerismo en auge y en los Estados del interior las partidas de bandoleros se presentan ya como tales, sin el recato que antes tenían de ampararse con alguna bandera política". ${ }^{60}$ Las apreciaciones del funcionario español coincidían con las de su homólogo estadounidense. Según este último, las autoridades militares tenían cada vez más dificultades para mantener la lealtad de los soldados debido a la escasez de fondos. ${ }^{61}$

Vale resaltar que en este periodo, los grupos que operaban de forma independiente en Chihuahua, generalmente eran designados como villistas y estos últimos como bandidos. ${ }^{62}$ A principios de 1917 los partes de las batallas del ejército constitucionalista denunciaban la existencia de un sinnúmero grupos armados dispersos de la División del Norte, que se internaban en la región serrana del estado. ${ }^{63}$ Evidentemente que los asaltos, pillajes y atentados en contra de las personas no eran acciones exclusivas de exvillistas. En este mismo año Francisco Murguía - general carrancista, jefe de operaciones en Chihuahua - recibió una circular, en la cual altos comandos del ejército constitucionalista exhortaban a los generales

a Estados Unidos. A principios de 1916 un grupo armado villista invadió a Columbus (Nuevo México) y atacó sorpresivamente a una guarnición en la zona fronteriza. Sin embargo, los villistas fueron sometidos rápidamente por las tropas de Estados Unidos. El resultado fue catastrófico para Villa, mientras que entre los estadounidenses se registraron 17 muertes - la mayoría civiles - se estima la pérdida de más de 100 villistas en esta campaña. In: Katz, op. cit., 1998, p. 560-566.

59 USA consuls, 07/octubre/1916, 27/octubre/1916, 02/noviembre/1916, 06/noviembre/1916, 09/noviembre/1916, 25/noviembre/1916, 04/diciembre/1916, cartas del cónsul T. D. Edwards al secretario de Estado, Washington; AHSDN, Fondo Revolución, 07/mayo/1916, caja 28, exp. XI/481.5/72, t. I, carta de I. L. Pesquera al general Luis Gutiérrez; 11/noviembre/1916, caja s/n, exp. XI/481.5/72, t. III, carta sin remitente.

60 AHEEM, 24/agosto/1916, legajo 1, no. 44, carta sin remitente.

61 USA consuls, 14/enero/1916, carta del cónsul T. D. Edwards al secretario de Estado, Washington.

62 USA consuls, 09/marzo/1917, carta del cónsul T. D. Edwards al secretario de Estado, Washington.

63 AHSDN, Fondo Revolución, 07/enero/1917, caja 29, exp. XI/481.5/76, t. I, carta al general Álvaro Obregón. 
y jefes a promover la disciplina entre sus miembros, debido a las constantes acusaciones, por parte de la población local, de depredaciones cometidas por sus tropas. ${ }^{64}$

La diseminación de estas partidas armadas en Chihuahua durante este periodo no se debía únicamente a la decadencia del villismo. Los abusos cometidos por los carrancistas eran ingredientes que agitaban aún más el complicado panorama de inseguridad que reinaba en el estado. En este contexto, los soldados independientemente de la autoridad superior buscaban soluciones individuales a las penurias de la prolongación del movimiento armado y a la merma del salario, ${ }^{65}$ como se percibe en el relato a continuación:

Una autoridad confiable me ha informado, que hay un bandidaje extendido en el norte de Chihuahua. Desde la semana pasada, los operadores de las minas, 80 millas al sur de El Paso, fueron obligados a suspender sus trabajos debido a la presencia de una banda de villistas que expulsó a los mineros de las explotaciones; robando sus provisiones; dispersando al ganado y quemando uno o más vagones [de trenes]. Mientras tanto soldados carrancistas han visitado el Rancho Fuller (Santo Domingo) que pertenece a inversionistas de California; apropiándose de ganado. [...]. También me han dicho que Palomas Land \& Cattle Co. que se encuentra en la franja fronteriza de México, al norte de Corralitos y Ojitos [...] ha sufrido continuas pérdidas de ganado, sus animales son arreados en partidas de 50 a 250 cabezas, que serán consumidas en Ascensión y en otras partes. 66

Por otro lado, ante el recrudecimiento de la situación militar, las guardias blancas empezaron a actuar de manera más "violenta". Daniel Nugent afirma que la hacienda San José de Babícora propiedad de William Randolph Hearst - permaneció intacta gracias a la actuación de estas fuerzas privadas. ${ }^{67}$ En estas circunstancias, ante el aumento de la inseguridad pública y de la debacle económica la población empezaba a buscar soluciones individuales para resolver sus penurias. 68 Hacia fines de la década de 1910 las noticias de asaltos, asesinatos y plagios formaban parte de la

64 AHSDN, Fondo Revolución, 25/enero/1917, caja 29, exp. XI/481.5/76, t. I, carta sin remitente.

65 La Patria, 22/julio/1919.

66 TWP, 10/junio/1918, caja 1, fólder 18, carta de E. C. Houghton. Traducción libre.

67 Nugent, op. cit., 1993, p. 78.

68 AHSDN, Fondo Revolución, 24/septiembre/1917, caja 30, exp. XI/481.5/76, t. IV, carta a Venustiano Carranza; 29/diciembre/1917, caja 31, exp. XI/481.5/76, t. VI, carta de Eugenio Martínez al coronel Bolívar Sierra; TWP, 13/diciembre/1917, caja 1, fólder 17, carta sin remitente; La Patria, 22/enero/1919. 
rutina regional y eran reseñadas en los periódicos de manera constante. ${ }^{69}$ En el marco de afianzamiento del gobierno carrancista y de sus instituciones, en los expedientes judiciales de este periodo ya se mencionaban los términos de la nueva constitución nacional para juzgar a los "ilegales".70 Es evidente que todos aquellos que no habían aceptado dicha autoridad eran considerados bandidos y perseguidos como criminales. En 1918, cuando se empezaba a retomar la marcha de la administración judicial en Chihuahua, se llevaron a cabo procesos criminales en los cuales se acusan a "muchos varios" vecinos de hacer intercambios con villistas que permanecían en las afueras de la capital del estado.71

Hacia 1919 algunos testigos que hacían un balance de las consecuencias de los combates en determinadas zonas de Chihuahua describían a Cuchillo Parado como una "ciudad de viudas y huérfanos". Otros informes señalaban que Ojinaga se encontraba en ruinas y la capital del estado no se quedaba atrás. ${ }^{72}$ En el plan económico, no obstante el optimismo de los reportes de las empresas mineras - los grandes emporios mineros continuaron funcionando a lo largo de la Revolución, tanto por el interés villista en ello, como debido a la demanda de minerales una vez iniciada la Primera Guerra Mundial73 - la situación en la industria ganadera no era ni de lejos comparable a la minera. ${ }^{74}$

69 La Patria, 22/enero/1919; 25/enero/1919; 09/abril/1919; 16/septiembre/1919; 03/octubre/1919; 14/octubre/1919; 06/marzo/1920; 08/marzo/1920.

70 ASTJECH, 04/febrero/1918, "Ejecutoria de la causa instruida contra Ignacio Sánchez por el delito de robo", sin clasificación.

71 ASTJECH, 02/marzo/1918, "Incidente de libertad bajo fianza promovido por el acusado de robo Jesús Herrera", sin clasificación.

72 TWP, 20/enero/1919, caja 1, fólder 20, carta de E. C. Houghton; El Paso Morning Times, 14/septiembre/1919.

73 El Paso Herald, 25/abril/1914; 05/noviembre/1914; 23/abril/1915. El Paso Morning Times, 15/noviembre/1919. A lo largo del periodo revolucionario estos dos periódicos dieron noticia de que la mayoría de las explotaciones mineras del estado funcionaron sin demasiados problemas y que incluso demandaban mano de obra, tal como se dio a conocer en 1915 en los minerales de Santa Bárbara.

74 Las propiedades ganaderas fueron presa de los grupos armados, pues el ganado imprescindible para el desplazamiento y alimentación de las tropas, era además "moneda de trueque" en el comercio de armas con los Estados Unidos y fue, por ejemplo, una de las principales fuentes de recursos del movimiento orozquista cuando éste desconoció a Madero; así como de la División del Norte durante la gestión villista en Chihuahua e incluso en el periodo en que los villistas actuaron como guerrilla. In: ALG, 12/marzo/1914, caja I, fólder C, docto. 37, carta de Francisco Villa a Lázaro de la Garza; La Patria, 16/enero/1919; Machado, Manuel A. "The Mexican Revolution and the Destruction of the Mexican Cattle Industry", In: Southwestern Historical Quarterly, v. 79:1, 1975, p. 2-4. 
La ganadería chihuahuense sufrió un serio revés durante la década de 1910. De acuerdo con un reporte sobre la situación del intercambio de animales entre México y Estados Unidos, los abigeos eran los principales responsables por el agotamiento de ganado en Chihuahua. Por otro lado, partidas armadas de ladrones de ganado volvían a actuar con mayor ímpetu en la región fronteriza, causando serios conflictos entre mexicanos y estadounidenses. En 1920 el periódico La Patria publicó una serie de artículos sobre el tema, uno de ellos fue especialmente reiterativo al informar que era la octava vez que tropas estadounidenses entraban en territorio mexicano para perseguir abigeos:

Por la (sic) octava vez las tropas de este país [el periódico era publicado en El Paso-Texas] entran a México para capturar el ganado robado. Un grupo de mexicanos armados penetró a territorio americano, se apoderó de caballos y reses, volvió a cruzar a México; siendo perseguido por caballería americana.

Después de haber hecho una incursión en territorio americano, en medio de una tormenta de granizo el martes en la noche, pasando la corriente del Río Bravo, en las inmediaciones de Ruidosa y Candelaria, varios mexicanos que se dedicaban al robo de ganado, fueron perseguidos por tropas americanas [...].

Desde hace días que se ha notado que con frecuencia mexicanos armados hacían esta clase de incursiones a territorio americano, para apoderarse de ganado que pastaba en los ranchos cercanos a la frontera. 75

La "reconstrucción" de la industria ganadera también se veía afectada por la falta de confianza de los inversionistas extranjeros en México. Las partidas de abigeos - que en efecto no se diferenciaban en muchos aspectos a algunos grupos de antiguos revolucionarios - parecían actuar con más autonomía. Hacia la década de 1920 el representante de Corralitos afirmaba "es imposible permanecer en este país protegiendo a la propiedad y nuestros intereses sin enemistarse con los hacendados y bandidos. Diversos empleados nuestros han sido encarcelados por robo de ganado y hemos recobrado ganado de otros que han escapado. Las autoridades son muy lentas para actuar" ${ }^{76}$

75 La Patria, 03/abril/1919. Por lo menos durante los tres meses subsecuentes el mismo periódico hizo referencia al hecho, en 27/junio/1919 publicó otro artículo titulado: "El robo de ganado continua siendo en la frontera asunto de la atención internacional".

76 TWP, 25/octubre/1921, caja 1, fólder 23, carta de E. C. Houghton. Traducción libre; Aboites Aguilar, (en prensa), p. 19-20. 
En la zona fronteriza "ilegales" estadounidenses en contacto con exsoldados carrancistas o villistas, negociaban pertrechos de guerra en los cuarteles de Estados Unidos que luego eran vendidos a los mexicanos. ${ }^{.7}$ Un periódico de aquel país afirmaba que el bandolerismo en México se asimilaba a pequeñas señales de fuego que después de un largo incendio, se extinguían aquí mientras empezaban a aparecer por allá. ${ }^{78}$ En ciertos casos se nota una clara correspondencia entre bandolerismo y crimen, las tácticas de algunas bandas - compuestas entre 30 y 50 hombres - que atacaban a la estructura ferrocarrilera eran las mismas de la época revolucionaria, como se reportó en un ataque en Jiménez al ferrocarril que transportaba minerales y en un asalto a un tren de pasajeros en estación Escalón. ${ }^{79}$ En otros casos todo indica que el delito estaba vinculado a la desocupación. Un ejemplo parece ser el de Jesús Rentería acusado del secuestro de dos tenientes norteamericanos en Chihuahua,

Hace algunos días crucé a México en compañía de cuatro amigos, esperando alguna oportunidad de hacer dinero, pues había estado sin trabajo durante muchos meses, y por fortuna la oportunidad que tuve fue magnifica. Un día estábamos vagando por el distrito de Ojinaga, cuando vimos a tres individuos como a una milla distante de nosotros. Al principio creímos que eran mexicanos de la patrulla de vigilancia, pero después nos convencimos de que eran viajeros. Tratamos de que nos entregaran todo lo que llevaban; pero desgraciadamente no tenían mucho. Entonces me saltó una idea, la de que los americanos eran oficiales de gobierno de Estados Unidos, y de que deteniéndolos podían pagar algún rescate... ${ }^{80}$

Es muy difícil, quizá imposible, reconstruir a la historia de los "actores menores" que engrosaron las filas de los ejércitos revolucionarios. Sin embargo, casos col el de Jesús rentaría quien firmó como capitán $2^{\circ}$. el manifiesto de Tlahualilo, según el cual las fuerzas villistas depondrían sus armas y se suspenderían

77 La Patria, 14/febrero/1919; 25/marzo/1919; 10/abril/1919; 14/octubre/1919; 06/dicembre/1919; El Paso Morning Times, 02/septiembre/1919; 15/septiembre/ 1919.

78 El Paso Morning Times, 19/octubre/1919; TWP, 25/octubre/1921, caja 1, fólder, 23, carta de E. C. Houghton; AHSDN, Fondo Revolución, 14/agosto/1919, caja 31, exp. XI/481.5/78, t. I, carta de J. M. M. Diéguez al general Francisco González; USA consuls, 08/septiembre/1919, 12/abril/1920, cartas de J. B. Stewart al departamento de Estado, Washington.

79 USA consuls, 08/septiembre/1919, 12/abril/1920, cartas de J. B. Stewart al departamento de Estado, Washington.

80 La Patria, 30/agosto/1919. 
las hostilidades 81 - y sus cuatro "compañeros" son una muestra de la desorganización social de los últimos años de combates armados en Chihuahua. Como ellos muchos exrevolucionarios continuaban "en pie de lucha" en busca de una "oportunidad". La prolongación del movimiento armado, las indecisiones político-militares, el debilitamiento de la situación económica, al lado de la propia violencia que muchos soldados habían enfrentado a lo largo de los combates, eran en parte responsables del desajuste social. No se puede dejar de mencionar que la desorganización del sistema judicial y la fragilidad general de los gobiernos acabaron por delegar a los particulares la tarea de perseguir a los delitos y "juzgar" a los criminales.82 Pero más que al bandolerismo en sí, el nuevo régimen tuvo que enfrentar un sentimiento de desilusión generalizado, era evidente que muchos contemporáneos estaban "cansados de la Revolución". La popularidad de las Defensas Sociales ${ }^{83}$ es una muestra de que la gente anhelaba volver a sus actividades y como lo dijo un exrevolucionario: "...pues ya era un desorden, era un bandidaje que ya no se podía...". .84

\section{Consideraciones finales}

Pese a todos los matices que se debe hacer acerca del hecho de que después de 1915 el bandolerismo - a que se hace referencia en la documentación - se confunde, en diversos aspectos, con las facciones revolucionarias dispersas en todo México, no se puede dejar de mencionar que el deterioro económico y la propia

81 JAURRIETA, José María. Con Villa (1916-1920), memorias de campaña. México: Consejo Nacional para la cultura y las Artes, 1997, p. 271-273.

82 En 1919 la Escuela de Jurisprudencia fue reinstalada en Chihuahua, pues debido a la ausencia de profesionales capacitados se estaban nombrando demasiados jueces legos para ejercer funciones judiciales. In: POECH, 25/octubre/1919; 11/marzo/ 1920.

83 A principios de 1916 el gobernador provisional Ignacio Enríquez convocó a los vecinos del estado a formar cuerpos paramilitares - que más tarde serían las llamadas Defensas Sociales - con el objetivo inicial de proteger a los intereses y vidas de los ciudadanos del estado "contra las depredaciones, abusos y crímenes de que puedan ser objeto por salteadores y bandoleros que sin bandera alguna, siembran por dondequiera la desconfianza, la miseria y la ruina”. Sin embargo, según Martha E. Rocha Islas tal medida fue antes que nada, uno de los mecanismos "legales" del gobierno carrancista para combatir a la guerrilla villista. In: ROCHA ISLAS, Martha Eva. Las defensas sociales en Chihuahua. México: Instituto Nacional de Antropología e Historia, 1988, p. 65.

84 Archivo de la Palabra, PHO/1/121, Jacobo Estrada entrevistado por María Alba Pastor, 31/octubre/1973. 
prolongación del conflicto armado fueron motivos que alejaron a ciertos individuos de sus grupos de origen. Este bandolerismo "autónomo" - que Alan Knight denominó "residuo de la revolución", ${ }^{85}$ - a cada día parecía apartarse más de sus bases y perder el apoyo popular. Se podría decir que con el pasar de los años algunos exrevolucionarios se convirtieron en bandidos "profesionales". Los miembros de estas bandas ya no eran villistas o carrancistas, sino desertores que intentaban aprovecharse de la situación, o en otros casos simplemente subsistir. Para conocer con mayor profundidad el comportamiento de estas bandas se podría seguir la trayectoria de algunos de sus miembros, a fin de percibir en qué medida fueron se apartando de los ideales y líderes revolucionarios. Los datos aquí analizados sólo nos permiten presentar un mosaico de impresiones y opiniones que se inclinaban a cuestionar - sin que ello fuera un sentimiento generalizado - la permanencia de ciertas facciones armadas después de 1915. En estos documentos, más que una crítica a la legitimidad de estos grupos, se hacia patente la intención de que la sociedad regresara al "orden" y evidentemente la presencia de estos exrevolucionarios minaba estas aspiraciones.

85 Knight, op. cit., 1996, p. 959-960, v. 2. 